\title{
AVALIAÇÃO DE INDICADORES DE QUALIDADE DE ÁREAS VERDES URBANAS: UMA FERRAMENTA AUXILIAR NA GESTÃO DE CIDADES
}

Evaluation of quality indicators of urban green areas: an assistant tool in the city management

Evaluación de indicadores de calidad de zonas verdes urbanas: una herramienta auxiliar en la gestión de la ciudad

\section{Maria de Nazaré Eufrásio Alves ${ }^{1}$, Ana Cláudia Melo Silva², Marcos de Miranda Leão Leite ${ }^{3}$}

\section{RESUMO}

Áreas verdes urbanas contribuem para a qualidade de vida nas cidades uma vez que desempenham um importante papel ambiental, paisagístico e psicossocial. O presente trabalho teve como objetivo realizar uma avaliação qualitativa de três áreas verdes da cidade de Sobral-CE. O instrumento de coleta de dados que orientou a avaliação dos espaços era composto por 26 variáveis relacionadas a seis parâmetros. Para cada uma das variáveis, foi atribuído um escore, associado a categorias, como indicador de seu status qualitativo (1- não se aplica; 2 - ruim; 3 - regular; 4 - bom; 5 - ótimo). Os resultados indicaram que o parâmetro Arborização foi o mais bem avaliado nas três áreas. Contudo, discrepâncias foram observadas em relação aos parâmetros Manutenção, Acessibilidade e Conforto entre os três locais. Esse diagnóstico pode contribuir para que o poder público promova a adequação desses critérios de forma a equalizar os padrões de qualidade entre esses espaços públicos.

Palavras-chave: Qualidade de vida; Cidades sustentáveis; Planejamento Urbano.

\footnotetext{
Graduanda em Psicologia,UFCG

2 Acadêmica de Direito pelo Centro Universitário UNINTA, Administradora de empresas

${ }^{3}$ Doutor em Ecologia e Recursos Naturais pela Universidade Federal do Ceará, Professor na Faculdade Luciano Feijão
} 


\section{ABSTRACT}

Urban green spaces contribute to quality of life, in the cities, because its play an important role of environmental, landscape and psychosocial aspects. The present work aimed to carry out a qualitative evaluation of three green spaces in Sobral city - CE. The data collection was guided with a spreadsheet wich composed of 26 variables related to six parameters. A score was assigned to each of the variables, associated with categories, as an indicator of their qualitative status (1- not applicable; 2 - poor; 3 - fair; 4 - good; 5 - excellent). The results indicated that the parameter Afforestation was better evaluated in the three areas. However, discrepancies were observed in relation to the Maintenance, Accessibility and Comfort parameters between the three locations. This diagnosis can contribute for the public authorities to promote the adequacy of these criteria in order to equalize the quality standards among these public spaces.

Keywords: Quality of life; City sustainability; Urban Planning.

\section{RESUMEN}

Las áreas verdes urbanas contribuyen a la calidad de vida en las ciudades, ya que desempeñan un importante papel ambiental, paisajístico y psicosocial. Este trabajo tuvo como objetivo realizar una valoración cualitativa de tres áreas verdes de la ciudad de Sobral-CE. La recolección de datos se guió con un instrumento compuesto por 26 variables relacionadas con seis parámetros. A cada una de las variables se le asignó una puntuación, asociada a categorías, como indicador de su estado cualitativo (1- no aplica; 2 - pobre; 3 - regular; 4 - bueno; 5 - excelente). Los resultados indicaron que el parámetro Forestación fue el mejor evaluado en las tres áreas. Sin embargo, se observaron discrepancias en relación con los parámetros de Mantenimiento, Accesibilidad y Confort entre las tres ubicaciones. Este diagnóstico puede contribuir a que las autoridades públicas promuevan la adecuación de estos criterios para igualar los estándares de calidad entre estos espacios públicos. Palabras clave: Calidad de vida; Ciudad sustentable; Urbanismo. 


\section{INTRODUÇÃO}

As questões urbanas vêm gerando repercussão desde a segunda metade do século XX, no que diz respeito às suas modificações de paisagismo, infraestrutura e qualidade de vida (LONDE; MENDES, 2014). A poluição do ar e da água, enchentes, barulho em excesso, entre outros problemas urbanos, são agentes causadores de prejuízos à saúde física e mental da população (COSTA; COLESANTI, 2011). De acordo com esses autores, as áreas verdes urbanas têm sido discutidas, em diferentes trabalhos acadêmicos, como espaços mitigadores desses problemas . Segundo Amato-Lourenço et al. (2016), reconhecidamente, o contato com a natureza gera benefícios à saúde humana, tais como longevidade, diminuição de doenças cardiovasculares, obesidade, saúde mental e qualidade do sono assim como também minimiza a ocorrência de doenças cardiovasculares, propicia a baixa ocorrência da obesidade, proporciona uma melhor qualidade no desempenho da saúde mental e na melhora significativa na qualidade do sono.

As áreas verdes vêm ganhando importância como um dos elementos fundamentais que contribuem na melhoria da qualidade do ambiente e de vida, do bem-estar e da saúde da população urbana (CHIESURA, 2004; COSTA; COLESANTI, 2011; BARGOS; MATIAS, 2011; SZEREMETA; ZANNIN, 2013; SCHEUER; NEVES, 2016). A resolução CONAMA Nº 369/2006 define essas regiões vegetativas com a presença do verde em locais urbanos urbanas como: "o espaço de domínio público que desempenhe função ecológica, paisagística e recreativa, propiciando a melhoria da qualidade estética, funcional e ambiental da cidade, sendo dotado de vegetação e espaços livres de impermeabilização" (MINISTÉRIO DO MEIO AMBIENTE - MMA, 2019). Segundo Pimenta, Solino-Filho e Picoli (2013), enquadram-se nessa categoria: as praças, os jardins públicos, parques urbanos, os canteiros centrais e trevos de vias públicas. Essas dimensões compostas por matas têm como uma das principais funções possibilitar à população momentos de lazer e recreação em contato com a natureza, bem como em interação com outras pessoas (PIMENTA; SOLINO-FILHO; PICOLI, 2013).

As arborizações urbanas prestam serviços ambientais dentre os quais se destacam: a diminuição das temperaturas, redução do escoamento superficial da água e da concentração de poluentes atmosféricos, redução de ruídos e na incidência solar em pavimentos e construções, bem como no estoque de carbono. Além disso, também possui funções de ordem estética e recreativa (AMATO-LOURENÇO et al., 2016), conservação da biodiversidade urbana (BRUN; LINK; BRUN, 2007), atuando também como equipamentos indutores do turismo (FIGUEIREDO et al., 2013; MOREIRA; SILVA, 2013; RAIMUNDO; SARTI, 2016). Do ponto de vista psicológico, estudos têm demonstra- 
do evidências de associações positivas entre vivências em espaços verdes e saúde mental. Araya et al. (2007) verificaram que a ausência de áreas verdes em locais residenciais pode ser determinante na ocorrência de transtornos mentais comuns. Também observou-se um menor risco de morbidades psiquiátricas entre residentes que possuíam áreas verdes em seu entorno (ASTELL-BURT; MITCHELL; HARTIG, 2014), bem como redução do estresse, aumento do bem-estar associado à presença desses espaços (CHIESURA, 2004; THOMPSON et al., 2012).

Dessa forma, em um ambiente urbano, a criação, manutenção e qualidade das dimensões compostas por vegetação promovem serviços ambientais relevantes para a qualidade de vida e o bem-estar psicossocial das populações citadinas. Assim, espaços como esses devem possibilitar bem-estar físico e psíquico aos seres humanos, sendo que essa possibilidade advém do contato com a natureza assim como as interações que esse ambiente pode assegurar à sociedade (COSTA; COLESANTI, 2011), seja por meio da realização de atividades físicas e/ou contatos sociais ocorridos nesses espaços.

O presente trabalho se propôs a atender a demanda da Agenda 2030 para o Desenvolvimento Sustentável. Esse documento possui um plano de ação com 17 Objetivos de Desenvolvimento Sustentável e 169 metas (https://nacoesunidas.org/pos2015/ods12/). Dentre os objetivos, o objetivo 11 trata de "Tornar as cidades e os assentamentos humanos inclusivos, seguros, resilientes e sustentáveis". Dois itens desse ponto podem ser destacados: 11.6: “Até 2030, reduzir o impacto ambiental negativo per capita das cidades, inclusive prestando especial atenção à qualidade do ar, gestão de resíduos municipais e outros” e 11.7: “Até 2030, proporcionar o acesso universal a espaços públicos seguros, inclusivos, acessíveis e verdes, particularmente para as mulheres e crianças, pessoas idosas e pessoas com deficiência”.

A cidade de Sobral está situada no médio curso do rio Acaraú, inserida no semiárido nordestino, o qual é caracterizado pela irregularidade espaço-temporal na distribuição das chuvas, bem como próxima à linha do equador onde predomina maior incidência de radiação solar e consequentemente altas temperaturas (DUARTE; CARACRISTI, 2005). De acordo com esses autores, uma das principais condicionantes socioambientais dos parâmetros climáticos locais é a urbanização crescente e desordenada. Ao construir, pavimentar e desmatar, para a expansão urbana, são gerados efeitos no ciclo hidrológico e trocas de calor, por meio da radiação incidente refletida pelas superfícies locais, condicionando o aumento das temperaturas. Portanto, em função dessas questões e das características climáticas de Sobral, a criação, manutenção e avaliação da qualidade de áreas verdes urbanas são imperativas, a fim de promover os benefícios proporcionados por esses espaços do ponto de vista ecológico/ambiental e psicossocial com vistas ao aumento da qualidade de vida da população. 


\section{OBJETIVO}

O presente trabalho teve como objetivo avaliar a condição de áreas verdes urbanas do município de Sobral, Ceará, aferindo a qualidade desses equipamentos, com vistas a contribuir para a formulação de políticas públicas que norteiem planos de qualificação desses espaços.

\section{METODOLOGIA}

Este estudo foi produto de um projeto de extensão de caráter interdisciplinar, projeto esse que foi apoiado pela Coordenadoria de Extensão da Faculdade Luciano Feijão, instituição de ensino superior com área de abrangência na cidade de Sobral-Ce e região. Sua relevância é referente à existência de um diálogo entre o Meio Ambiente e a Psicologia, uma vez que muitos autores reportam que a manutenção e implementação das áreas verdes é uma forma de promover a saúde, qualidade ambiental e bem-estar psicossocial. Além de consistir em uma forma de fomento às práticas de extensão dentro e fora da universidade, dando a oportunidade de interlocução de saberes teóricos com os encontrados em campo. O tripé ensino, pesquisa e extensão, precisa ser cada vez mais fomentado e construído de modo a comunicar, incluir e intermediar processos que são da ordem do palpável. Além do mais, Alves e Nogueira Neto (2019) afirmam que esse tripé é fonte de sensibilização e de alcance de um aprendizado imensurável. Por uma questão central, que é realizar pesquisa junto com as pessoas ou elementos que são pesquisados, o fazer junto impacta fortemente no processo e nos resultados. A extensão universitária é hoje uma grande mediadora do acadêmico à comunidade e da comunidade ao universo acadêmico, rompendo assim com os modelos normativos e segregadores que o setor acadêmico ainda produz.

O presente estudo foi realizado na cidade de Sobral ( $3^{\circ} 41^{\prime} 10^{\prime \prime} \mathrm{S} ; 40^{\circ} 20^{\prime} 59^{\prime \prime} \mathrm{W}$ ), na região norte do estado do Ceará. A área é caracterizada por um clima tropical semiárido brando com temperatura média variando entre $26^{\circ}$ e $28^{\circ} \mathrm{C}$ (IPECE, 2012). Os locais formados por vegetações tiveram como critério de escolha, a consulta realizada em parceria com a Secretaria de Desenvolvimento Urbano e Meio Ambiente via Autarquia Municipal de Meio Ambiente de Sobra (AMA). As áreas selecionadas, Praça de Cuba, Margem Esquerda do rio Acaraú e Parque da Cidade, foram avaliadas nos dias 9, 23 e 30 de novembro de 2017, respectivamente. Em que essas áreas foram escolhidas por sua relevância ambiental, paisagística e social para a cidade, bem como por serem centrais e de fácil acesso pela população local. Na avaliação qualitativa, foram considerados os aspectos urbanístico-estéticos, ecológicos e sociais, bem como foi levado em conta o estado de conservação dos equipamentos dessas áreas (SANTOS, 2017). 
O procedimento foi realizado a partir de um censo orientado por uma planilha de observação proposta por Santos (2017), onde foram avaliadas a disponibilidade e a qualidade dos equipamentos, considerando-se seis parâmetros: Conforto, Manutenção, Lazer, Acessibilidade, Socialização e Arborização, os quais são compostos por 26 variáveis. A avaliação qualitativa destas variáveis foi realizada pela atribuição de escores associados às seguintes categorias: 1 (não se aplica - ausência de estrutura ou equipamento); 2 (ruim); 3 (regular); 4 (bom) e 5 (ótimo), (modificado de Santos, 2017). Com vistas a minimizar a subjetividade na avaliação, a atribuição do escore para cada uma das variáveis foi efetuada mediante uma decisão consensual, durante as campanhas de campo, entre três avaliadores, os quais faziam parte da equipe de trabalho. $\mathrm{O}$ escore predominante, dentre as variáveis, definiu o status qualitativo do parâmetro.

\section{RESULTADOS E DISCUSSÃO}

$\mathrm{Na}$ avaliação da qualidade das áreas verdes urbanas (praças), considerando a Praça de Cuba, os parâmetros Arborização, Manutenção, Socialização e Acessibilidade obtiveram o status qualitativo predominante "Ótimo". Em virtude da maior parte das variáveis que formam esses parâmetros estarem presentes em quantidade adequada, integradas e bem distribuídas no equipamento. Todavia, registrou-se, na inspeção do local, a ausência de alguns itens importantes como "sinalização turística”. Os parâmetros Lazer e Conforto mostraram um desempenho insatisfatório em função da maioria das variáveis que os compõem não estarem presentes junto ao equipamento. Embora, "bancos”, "lixeiras" e "iluminação" (Conforto) e "local com cobertura" (Lazer), tenham sido bem avaliados.

Na Margem Esquerda (rio Acaraú), o parâmetro mais bem avaliado foi Arborização. Foi observada uma diversificação quanto aos estratos vegetais presentes nessa área, bem como o projeto paisagístico também contribuiu para a boa avaliação desse parâmetro. De uma forma geral, o parâmetro Socialização também foi bem avaliado nesse equipamento em função da presença e integração ao espaço de estruturas que permitem a ocorrência de eventos e interações sociais. Entretanto, as variáveis associadas aos parâmetros Acessibilidade, Lazer e Conforto, tiveram um desempenho insatisfatório na avaliação variando de "ruim" a "não se aplica", indicando ausência e/ou má conservação de componentes da infraestrutura relativas à composição desses parâmetros.

No Parque da Cidade, os parâmetros Arborização, Socialização e Acessibilidade, foram avaliados como "ótimo". Nessa área, destacou-se a cobertura vegetal diversificada com todos os estratos vegetais presentes. Com relação ao parâmetro Acessibilidade, o Parque da Cidade permite uma fácil chegada ao local e dispõe de amplo espaço para estacionamento. Foram registradas na 
inspeção de campo, a presença de rampas para deficientes, as quais estavam bem distribuídas pela estrutura, bem como pontos de transporte público. Esse espaço também possui uma infraestrutura física com a presença de equipamentos para eventos e interações sociais. Dentre os aspectos com avaliação insatisfatória, estão as variáveis associadas aos parâmetros Lazer e Manutenção, tais como a má conservação de equipamentos de lazer infantil e adulto e ausência dos responsáveis pela limpeza e manutenção, respectivamente, no momento da visita. Além disso, verificou-se uma má distribuição e pouca quantidade de lixeiras em relação à extensão do local. Esses resultados estão sumarizados na tabela 1.

Tabela 1. Áreas verdes avaliadas. Escores atribuídos às variáveis e seus respectivos parâmetros, como indicação do status qualitativo

\begin{tabular}{|c|c|c|c|c|}
\hline & & PRAÇA DE CUBA & MARGEM ESQUERDA & PARQUE DA CIDADE \\
\hline PARÂMETROS & VARIÁVEL & & ESCORES & \\
\hline \multirow{6}{*}{ Conforto } & Bancos & 5 & 3 & 4 \\
\hline & Lixeiras & 4 & 2 & 2 \\
\hline & Banheiro & 1 & 1 & 3 \\
\hline & Bebedouro ou chafariz & 1 & 1 & 3 \\
\hline & Iluminação & 5 & 4 & 5 \\
\hline & Telefone público & 1 & 1 & 1 \\
\hline \multirow{5}{*}{ Lazer } & Equipamento de Lazer infantil & 1 & 1 & 2 \\
\hline & Equipamentto de lazer adulto & 1 & 1 & 2 \\
\hline & Local com cobertura & 4 & 3 & 2 \\
\hline & Quadra esportiva & 1 & 5 & 3 \\
\hline & Banca de revista & 1 & 1 & 1 \\
\hline \multirow{5}{*}{ Acessibilidade } & Estacionamento & 4 & 2 & 5 \\
\hline & Piso, calçada, pavimentação & 5 & 3 & 4 \\
\hline & Rampa para deficientes & 5 & 2 & 5 \\
\hline & Sinalização turística & 1 & 2 & 2 \\
\hline & Ponto de taxi/ônibus & 5 & 2 & 5 \\
\hline \multirow[b]{3}{*}{ Socialização } & Palco/coreto & 1 & 4 & 5 \\
\hline & Obra de arte & 5 & 5 & 5 \\
\hline & Local para manifestação religiosa & 5 & 4 & 5 \\
\hline \multirow{3}{*}{ Manutenção } & Responsável pela limpeza & 5 & 3 & 2 \\
\hline & Responsável pela segurança & 4 & 3 & 5 \\
\hline & Responsável pela manutenção & 5 & 2 & 2 \\
\hline \multirow{4}{*}{ Arborização } & Canteiro & 4 & 3 & 2 \\
\hline & Árvore de porte arbustivo & 5 & 5 & 5 \\
\hline & Árvore de porte arbóreo & 5 & 5 & 5 \\
\hline & Paisagismo & 5 & 4 & 5 \\
\hline
\end{tabular}

Fonte: dados da pesquisa.

* Parâmetros e variáveis da tabela, baseados em Santos (2017).

** Status qualitativo: 1 (não se aplica); 2 (ruim); 3 (regular); 4 (bom); 5 (ótimo). 
Quando comparadas de forma geral, as três áreas possuem boas condições de arborização, apresentando vegetação nos três estratos: herbáceo, arbustivo e arbóreo. Tanto a Margem Esquerda quanto o Parque da Cidade necessitam de mais atenção no que se refere aos aspectos relacionados ao parâmetro Manutenção e, em contrapartida, a Praça de Cuba apresentou condições satisfatórias nesse quesito. No parâmetro Socialização, as três áreas foram bem avaliadas, de uma forma geral, uma vez que foi registrada a presença de estruturas, equipamentos e espaço disponível para o exercício dessa função. O parâmetro Acessibilidade precisa ser melhorado na Margem Esquerda, sobretudo, em pontos relacionados à sinalização turística, rampa para deficientes e pontos para transporte público. Lazer e Conforto foram dois parâmetros que tiveram sua avaliação comprometida nas três áreas pelo fato de variáveis associadas a esses aspectos não estarem disponíveis nesses espaços, principalmente equipamentos de lazer infantil e adulto, bancas de revista e telefones públicos. Os resultados comparativos dos parâmetros entre as três áreas podem ser visualizados na figura 1 .

Figura 1. Comparativo do status qualitativo dos parâmetros avaliados entre os três equipamentos.

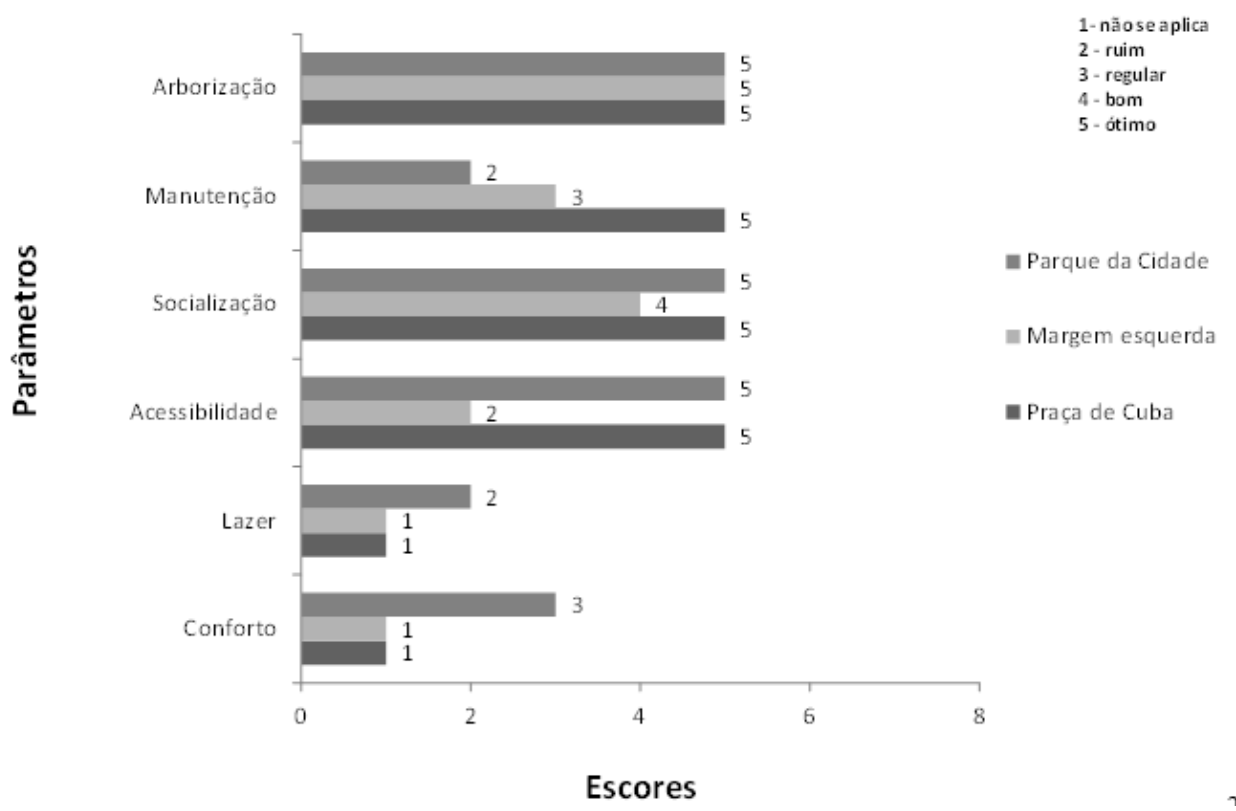

O parâmetro Arborização teve seu status qualitativo predominante enquadrado como "ótimo" nas três áreas de estudo. Esses resultados indicam que os três equipamentos possuem boa cobertura vegetal, que varia desde plantas de porte arbustivo até arbóreo. Dessa forma, esses equipamentos atendem, potencialmente, à função de prestar serviços ecológico/ambientais, sobretudo, no que se refere à diminuição do desconforto térmico e regulação microclimática da cidade, aumento da superfície de solo permeável, atenuando os danos da urbanização (DUARTE; CARACRISTI, 2005; 
BARGOS; MATIAS, 2011; AMATO-LOURENÇO et al., 2016; SCHEUER; NEVES, 2016). Em virtude de sua boa cobertura vegetal, essas áreas também podem contribuir para a qualidade do ar com redução de poluentes particulados e gasosos, diminuição de ruídos, bem como para a manutenção e conservação da biodiversidade nos ambientes urbanos e beleza cênica (BRUN et al., 2007; AMATO-LOURENÇO et al., 2016). Além dos benefícios de ordem ambiental, esses espaços verdes podem contribuir positivamente para o bem-estar psicológico da população, uma vez que esses ambientes podem propiciar a integração entre as pessoas e a natureza, refúgio do caos urbano, relaxamento e redução do estresse (CHIESURA, 2004; COSTA; COLESANTI, 2011; THOMPSON et al., 2012; LONDE; MENDES, 2014; SCHEUER; NEVES, 2016).

De acordo com os critérios propostos para a Socialização, os três equipamentos foram bem avaliados, no geral. Na Margem Esquerda, foi constatada, em campo, a utilização desse local para a realização de atividades físicas por parte dos frequentadores avistados no dia da inspeção, bem como de estruturas que permitem a realização de eventos, assim, potencializando as interações sociais, vivências de lazer entre os frequentadores do local e, desse modo, otimizando os benefícios psicossociais proporcionados pelas áreas verdes urbanas (COSTA, 2011; FIGUEIREDO et al., 2013; PIMENTA et.al., 2013).

No parâmetro Manutenção, a Praça de Cuba se sobressaiu em relação aos outros equipamentos. Isso é um indicador de que esse espaço é bem zelado refletindo em sua beleza cênica e paisagística. Contudo, esse parâmetro precisa ser melhor trabalhado nos outros espaços verdes, pois esse quesito inclui segurança e limpeza (SANTOS, 2017), pontos fundamentais para que esses locais sejam ocupados e utilizados. Segundo Costa e Colesanti (2011), praças sofrem também com problemas de manutenção e zeladoria, o que prejudica o usufruto desses espaços pela população. Dessa forma, cabe a gestão pública implementar intervenções para a mitigação desses problemas pontuados na avaliação. A avaliação do parâmetro Acessibilidade, na Margem Esquerda, indicou que essa área está deficitária em aspectos como estacionamento, rampa para deficientes, piso, pavimentação, calçadas e sinalização turística. Assim, esse quesito deve ser visto com mais atenção pela gestão pública no planejamento urbano de forma a promover uma melhor chegada ao local, permanência e deslocamento pela área.

O parâmetro Conforto, que inclui a presença de bancos, lixeiras, banheiros, iluminação entre outros (SANTOS, 2017), foram mais bem avaliados na Praça de Cuba e Parque da Cidade. Logo, as variáveis desse parâmetro precisam ser melhores observadas na Margem Esquerda, por meio do planejamento e intervenções do poder público. Londe e Mendes (2014) ressaltam que, no contexto da qualidade de vida urbana, para as áreas verdes urbanas contribuírem para o desenvolvimento 
social, bem como promover benefícios do ponto de vista da saúde física e psíquica da população, faz-se necessário que esses equipamentos sejam dotados de infraestrutura adequada, segurança, equipamentos e outros fatores que as tornem atrativas à população e, portanto, serem efetivamente ocupadas.

Para o presente estudo, vale salientar que a coleta de dados se deu de forma pontual. O trabalho de campo foi realizado durante um intervalo de tempo determinado e específico em função das condições logísticas e operacionais dos avaliadores. Dessa forma, por exemplo, variáveis de parâmetros como Manutenção (responsáveis pela limpeza, segurança e manutenção) podem ter sido subestimadas ou superestimadas, uma vez que estas foram avaliadas na ocasião da visita aos locais. Assim, a presença ou ausência desses agentes no momento da coleta de dados pode ter aumentado ou diminuído o status qualitativo desse parâmetro. Portanto, estudos posteriores com esse enfoque devem levar em conta essa limitação e na medida do possível, do ponto de vista logístico e operacional, aumentar o tempo de observação, sobretudo, no que concerne a esse aspecto.

\section{CONSIDERAÇÕES FINAIS}

O parâmetro Arborização atingiu o conceito máximo estabelecido nas três áreas, indicando que o grau de cobertura vegetal dos equipamentos está adequado para as áreas verdes avaliadas. No entanto, observaram-se discrepâncias, sobretudo, no que se refere à Manutenção Acessibilidade e Conforto entre os três locais, dando indicações para que o poder público municipal promova a adequação desses critérios de avaliação de forma a equalizar os padrões de qualidade entre esses espaços públicos.

O parâmetro Lazer necessita de uma atenção maior da gestão pública, pois dos critérios avaliados, foi o que obteve o pior desempenho nas três áreas. Tendo em vista a importância das praças na interação social, no bem-estar físico e psicológico das pessoas, é necessário a disposição de estruturas que proporcionem a realização de atividades lúdicas, recreação e divertimento para os frequentadores desses locais.

A avaliação de áreas verdes urbanas pode se constituir em uma poderosa ferramenta que pode ser aliada na gestão das cidades, pois fornece um diagnóstico sobre a situação desses espaços apontando fortalezas e fragilidades. Desse modo, orientam o poder público em ações de melhoria desses equipamentos para que estes possam exercer seus papéis ecológico/ambientais, estético/paisagísticos e psicossociais de forma satisfatória. A boa condição desses espaços é fundamental para a promoção da qualidade de vida das populações citadinas, contribuindo, inclusive, para a contemplação 
de alguns dos objetivos da Agenda 2030 para o desenvolvimento sustentável.

\section{AGRADECIMENTOS}

À Coordenadoria de Extensão da Faculdade Luciano Feijão pela oportunidade de desenvolvimento do projeto "Áreas verdes urbanas como provedoras de qualidade de vida: avaliação de infraestruturas verdes da cidade Sobral- Ce", do qual foi extraído este artigo. Agradecemos, também, à Agência de Meio Ambiente de Sobral (AMA) e à Guarda Municipal de Sobral.

\section{REFERÊNCIAS}

ALVES, Maria De Nazaré Eufrásio; NETO, José Maria Nogueira. "NO MÊI DO MUNDO": AS ANDANÇAS QUE POTENCIALIZAM O ENSINO, A PESQUISA E A EXTENSÃO. Sobral(CE) UFC, 2019. Disponível em: <https//www.even3.com.br/anais/VSP/239964-NO-MEI-DO-MUNDO--AS-ANDANCAS-QUE-POTENCIALIZAM-O-ENSINO-A-PESQUISA-E-A-EXTENSAO >. Acesso em: 01 mar.2021

AMATO-LOURENÇO, L.F.; MOREIRA, T.C.L.; ARANTES, B.L.; SILVA-FILHO, D.F.; MAUAD, T. Metrópoles, cobertura vegetal, áreas verdes e saúde. Estudos Avançados, v. 30, n. 86, p. 113$130,2016$.

ARAYA, R.; MONTGOMERY, A.; ROJAS, G.; FRITSCH, R.; SOLIS, J.; SIGNORELLI, A.; LEWIS, G. Common mental disorders and the built environment in Santiago, Chile. British Journal of Psychiatry, v. 190, p. 394-401, 2007.

ASTELL-BURT, T.; MITCHELL, R.; HARTIG, T. The association between green space and mental health varies across the lifecourse. A longitudinal study. J Epidemiol Community Health, v. 0, p. $1-6,2014$.

BARGOS, D.C.; MATIAS, L.F. Áreas verdes urbanas: um estudo de revisão e proposta conceitual. Revista da Sociedade Brasileira de Arborização Urbana, v.6, n.3, p. 172-188, 2011.

BRUN, F.G.K; LINK, D; BRUN, E.J. O emprego da arborização na manutenção da biodiversidade de fauna em áreas urbanas. Revista da Sociedade Brasileira de Arborização Urbana, v. 2, n. 1, p. 117-127, 2007.

CHIESURA, A. The role of urban parks for the sustainable city. Landscape and Urban Planning, v. 68, p. 129-138, 2004.

COSTA, R.G.S; COLESANTI, M.M. A contribuição da percepção ambiental no estudo das áreas verdes. Raega, v. 22, p. 238-251, 2011.

DUARTE; J.S.S; CARACRISTI, I. Clima e qualidade de vida na cidade de Sobral: buscando a dimensão cotidiana dos estudos climáticos. Revista da Casa da Geografia de Sobral, v. 6/7, n. 1, p. 95-108, 2004/2005.

FIGUEIREDO, S.L.; BAHIA, M.C.; CABRAL, P.T.M., NÓBREGA, W.R.M., TAVARES, A.E.P. Lazer, esporte e turismo: a importância, lazer e uso das áreas verdes urbanas em Belém/Brasil. Licere, v. 16, n. 1, p. 2-28, 2013.

IPECE. Perfil Básico Municipal 2012 - Sobral. Governo do Estado do Ceará, 2012.

LONDE, P. R; MENDES, P.C. A influência das áreas verdes na qualidade de vida urbana. Hygea, 
v. 10, n. 18, p. 264-272, 2014.

MINISTÉRIO DO MEIO AMBIENTE. Áreas verdes urbanas. Disponível em: http://www.mma. gov.br/informma/itemlist/category/61-areas-verdes-urbanas. Acesso em: 20. Set. 2018.

MOREIRA, J.F.; SILVA, C.A. Paisagem e mídia: os parques urbanos como produto turístico e imobiliário em Goiânia-GO. Caminhos de Geografia, v. 14, n. 46, p. 220-235, 2013.

PIMENTA, N.C.; SOLINO-FILHO, T.; PICOLI, R.L. Ecossistemas urbanos e a conservação da biodiversidade: benefícios sociais e ambientais do parque de uso múltiplo da Asa Sul. IV Congresso Brasileiro de Gestão Ambiental. Salvador, 2013. Disponível em: www.ibeas.org/congresso/ Trabalhos2013/VI059.pdf. Acesso em: 08. set. 2017.

RAIMUNDO, S.; SARTI, A.C. Parques urbanos e sue papel no ambiente, turismo e lazer na cidade. Revista Iberoamericana de Turismo, v. 6, n. 2, p. 3-24, 2016.

SANTOS, R.G. Proposição de um índice para avaliação e mapeamento de áreas verdes públicas (IQUAV): uma aplicação na área urbana de Poços de Caldas - MG. Bol. geogr., v. 35, n. 1, p. 64$81,2017$.

SCHEUER, J.M.; NEVES, S.A.M.S. Planejamento, áreas verdes e qualidade de vida. Revista Meio Ambiente e Sustentabilidade, v. 5, n. 11, p. 60-73, 2016.

SZEREMETA, B.; ZANNIN, P.H.T. A importância dos parques urbanos e áreas verdes na promoção da qualidade de vida em cidades. Raega, v. 29, p. 177-193, 2013.

THOMPSON, C.W.; ROE, J.; ASPINALL, P.; MITCHELL, R.; CLOW, A.; MILLER, D. More green space is linked to less stress in deprived communities: Evidence from salivary cortisol patterns. Landscape and Urban Planinng, v. 105, p. 221-229. 